\title{
Significance of stem cell marker Nanog gene in the diagnosis and prognosis of lung cancer
}

\author{
ZENG LIU $^{1}$, JING ZHANG ${ }^{2}$, HONGGANG KANG $^{2}$, GUIMING SUN ${ }^{2}$, \\ BAOZHONG WANG ${ }^{2}$, YANWEN WANG ${ }^{2}$ and MENGXIANG YANG ${ }^{2}$ \\ ${ }^{1}$ Department of Nuclear Medicine, Central Hospital of Xiangyang, Xiangyang, Hubei 441021; \\ ${ }^{2}$ Department of Oncology, Liaocheng People's Hospital, Liaocheng, Shandong 252000, P.R. China
}

Received March 8, 2016; Accepted July 28, 2016

DOI: $10.3892 / 01.2016 .4923$

\begin{abstract}
The aim of the present study was to analyze the stem cell marker, Nanog gene, for the diagnosis and prognosis of lung cancer cases, and to study its application in the diagnosis of lung cancer. In total, 100 patients diagnosed with lung cancer between April, 2013 and May, 2015 were included in the present study. The patients were randomly divided into group A (lung cancer) and group B (squamous cell lung carcinoma). RT-PCR was used to detect the cancer and adjacent tissues, and Nanog gene expression was detected in groups A and B in cells. The results showed that, analysis of Nanog gene expression in the two groups of patients varied to different degrees. There was no significant difference between the two groups with regard to age, gender, disease stage and lymph node metastasis. Nanog gene expression in patients with carcinoma were significantly higher than that in the adjacent tissues $(\mathrm{p}<0.05)$. By contrast, differentiated and well-differentiated carcinoma tissue showed a significantly higher Nanog gene expression than poorly differentiated and undifferentiated carcinoma $(p<0.05)$. The expression of Nanog in normal cells was significantly higher than that in normal lung tissues and benign lesions in lung cancer stem cells. Nanog was highly expressed in $\mathrm{CD}_{4} 4^{+}$cells, and Nanog expression in lung cancer stem cells was significantly higher $(\mathrm{p}<0.05)$. In conclusion, for groups A (lung cancer) and B (squamous cell lung carcinoma) the Nanog gene expression was significantly higher. The data of the present study show that the patients with stage III and IV lung cancer had a higher Nanog gene expression. In addition, there was a higher expression of Nanog in lung cancer patients. By contrast, a lower degree of cell differentiation was associated with strong Nanog gene expression in lung cancer.
\end{abstract}

Correspondence to: Dr Honggang Kang, Department of Oncology, Liaocheng People's Hospital, 67 Dongchang West Road, Liaocheng, Shandong 252000, P.R. China

E-mail: fes804888@163.com

Key words: Nanog gene, lung cancer, stem cells

\section{Introduction}

Tumors possess a self-renewing ability that can generate heterogeneous cells in tumor cells. Tumors are composed of somatic mutations, each of which can be grown without restriction. However, this does not explain the phenomenon that cancer cells seem to have unlimited viability, and that not all tumor cells are capable of unlimited growth. The characteristics of tumor cell growth, metastasis and recurrence are similar to the basic characteristics of stem cells. Therefore, the theory of tumor stem cells (TSCs) has been suggested (1). This theory provides a new direction and a visual angle to us to gain a new understanding of the origin and nature of the tumor, as well as the clinical treatment of cancer. In recent years, studies conducted in China have increasingly focused on cancer stem cells. The main reason leading to tumor is abnormality of stem cells, leading to diseases, such as lung and colorectal cancer (1). Current studies have shown that malignant tumor growth leads to the expression of stem cells in molecules that play an important role in gene regulation (2).

Investigations regarding Nanog gene have shown that it promotes cell induction, leading to analysis of Nanog gene expression in tumor (3), although its expression is relatively decreased in lung cancer (4). This study primarily investigated the role of Nanog gene in the two groups of patients with pulmonary adenocarcinoma and squamous lung carcinoma.

\section{Patients and methods}

Patients. In total, 100 cases of tumor patients diagnosed with lung cancer between April, 2010 and May, 2012 were selected for the present study. Patient age was 22-76 years, with an average age of $58.43 \pm 10.44$ years. The study included 50 men, aged 22-73 years, with an average age of $59.12 \pm 9.06$ years, and 50 women, aged 23-76 years, with an average age of $58.54 \pm 9.43$ years. A CT scan, MRI, chest X-ray, flexible bronchofiberscope examination and sputamentum cell examination were performed on the patients, for confirmation of lung cancer. In the 100 patients, there were 50 cases in group A (pulmonary adenocarcinoma) for whom the diagnosed age for 17 cases was $<40$ years, 16 cases were $40-60$ years, and 17 cases were $>60$ years. The tested diseases of this study were divided into 9 cases in phase I, 13 cases in phase II, 11 cases 
Table I. Nanog gene expression at different phases in pulmonary adenocarcinoma and squamous lung carcinoma patients.

\begin{tabular}{llclcc}
\hline & \multicolumn{2}{c}{ Pulmonary adenocarcinoma $(\mathrm{n}=50)$} & & \multicolumn{2}{c}{ Squamous lung carcinoma $(\mathrm{n}=50)$} \\
\cline { 2 - 3 } Phase & Cancer tissue & Adjacent normal tissue & & Cancer tissue & Adjacent normal tissue \\
\hline I phase & $1.30 \pm 0.29$ & $0.34 \pm 0.13^{\mathrm{c}, 1}$ & & $1.33 \pm 0.46$ & $0.36 \pm 0.14^{\mathrm{c}, 5}$ \\
II phase & $1.38 \pm 0.32$ & $0.36 \pm 0.14^{\mathrm{c}, 2}$ & & $1.58 \pm 0.40$ & $0.38 \pm 0.10^{\mathrm{c}, 6}$ \\
III phase & $2.28 \pm 0.52^{\mathrm{a}, \mathrm{b}, 9}$ & $0.44 \pm 0.11^{\mathrm{c}, 3}$ & & $2.33 \pm 0.58^{\mathrm{a}, \mathrm{b}, 11}$ & $0.42 \pm 0.15^{\mathrm{c}, 7}$ \\
IV phase & $2.47 \pm 0.63^{\mathrm{a}, \mathrm{b}, 10}$ & $0.43 \pm 0.15^{\mathrm{c}, 4}$ & & $2.56 \pm 0.60^{\mathrm{a}, \mathrm{b}, 12}$ & $0.47 \pm 0.13^{\mathrm{c}, 8}$ \\
\hline
\end{tabular}

Comparison of the data in phase $\mathrm{I}, \mathrm{t}_{9}=3.269, \mathrm{t}_{10}=5.212, \mathrm{t}_{11}=2.963, \mathrm{t}_{12}=3.214,{ }^{\mathrm{a}} \mathrm{P}<0.05$ to phase II, $\mathrm{t}_{9}=3.265, \mathrm{t}_{10}=5.231, \mathrm{t}_{11}=5.123, \mathrm{t}_{12}=2.152$, ${ }^{b} \mathrm{P}<0.05$. Comparison to cancer tissue, $\mathrm{t}_{1}=2.369, \mathrm{t}_{2}=2.963, \mathrm{t}_{3}=3.158, \mathrm{t}_{4}=5.156, \mathrm{t}_{5}=2.961, \mathrm{t}_{6}=2.485, \mathrm{t}_{7}=2.741, \mathrm{t}_{8}=2.852,{ }^{\mathrm{c}} \mathrm{P}<0.05$.

in phase III and 10 cases in phase IV. There were 21 patients with lymph node metastasis, as indicated by test. In addition, 50 cases were included in group B (squamous cell lung carcinoma). No significant difference with regard to age, gender and diseases were observed, compared with cases in group A.

Test methods of Nanog gene expression in tumor stem cells. RT-PCR was used to quantify Nanog gene in real-time. The mRNA agarose gel electrophoresis was used to test 100 cases, followed by $1 \mu \mathrm{g}$ of RNA for reverse transcription. PrimeScript RT was added to the $20 \mu 1$ system and reverse transcription was initiated initially at $42^{\circ} \mathrm{C}$ for $45 \mathrm{~min}$, followed by incubation at $70^{\circ} \mathrm{C}$ for $10 \mathrm{~min}$, and cooling on ice to inactivate reverse transcriptase. Subsequently, cDNA was synthesized. Primers were designed from GeneBank data as follows: Nanog forward, (5'-ATGCCTGCATTTTTCATCC-3') and reverse, (5'-GAGGCAGGTCTTCAGAGGAA-3'), with a product length of $189 \mathrm{bp}$. $\beta$-actin was used as the internal control and its primers were: Forward, (5'-CAGAGCAAGAGAGGC ATCC-3') and reverse, (5'-CTGGGGTGTTGAAGGTCTC-3'), with a product length of $217 \mathrm{bp}$. PCR reaction was prepared by using $2 X$ SYBR Premix Ex Taq $10 \mu 1$, cDNA template $2 \mu 1$, forward and reverse primers of $0.4 \mu \mathrm{l}$, and the total volume was brought to $20 \mu \mathrm{l}$ with autoclaved water. Clinical SYBR-Green I fuel method was used for RT-PCR to amplify the genes. Fully automatic fluorescent quantified PCR apparatus AB17500, and Real-Time PCR system, were used and the temperature was set at $58^{\circ} \mathrm{C}$ for 39 cycles. Following observation the results were recorded. The relative $\mathrm{CT}$ value for $\beta$-actin was calculated in detail as indicated in a previous study (5-8).

Observation index. The real-time quantified method was used to examine age, gender, and any lymph node metastasis in the two groups of patients. RT-PCR of tumor and adjacent normal tissue was used to test the gene expression level of stem cells of the two groups of patients. After obtaining the data, the gene expression amount of groups A and B was analyzed to varying extent (7). PCR gel electrophoresis was used to test Nanog expression in $\mathrm{CD}_{4} 4^{+}$cells, and the living curve was used for statistics and to compare the survival rate of the patients in five years. In addition, immunostaining was performed to stain lung cancer cells in patients.

Statistical analysis. The data were presented as mean \pm standard deviation. Quantified data were expressed by cases (n)

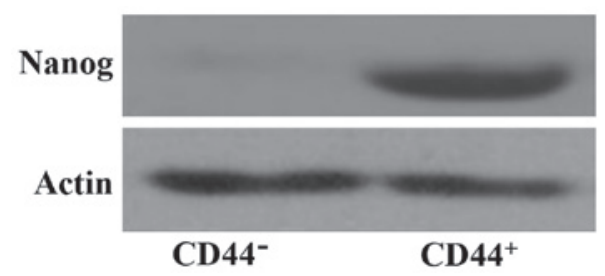

Figure 1. Nanog expression in lung cancer stem cell CD44+ cells.

and percentage. Data analysis was conducted using SPSS 15.0 software (Chicago, IL, USA). A Student's t-test and $\chi^{2}$ test were used to compare data. The ranked data were compared by a non-parametric test. $\mathrm{P}<0.05$ was considered to indicate a statistically significant difference.

\section{Results}

Nanog expression in $\mathrm{CD}_{4} 4^{+}$cells in lung cancer stem cell. As shown in Fig. 1, the lung cancer stem cells CD44 ${ }^{+}$cells showed a higher expression of Nanog, suggesting that it plays an important role in lung cancer stem cells.

Nanog expression in adjacent normal tissue and benign lesion cancer tissue. The results showed that Nanog was mainly expressed in the nucleus of lung cancer cells, and in positive control (spermatogenous cell). The expression was mainly in the nucleus, and Nanog expression in lung cancer cells was significantly higher than that of adjacent normal tissue and benign lesion lung tissue (Fig. 2).

Nanog gene expression. We found that the expression level of phase I patients was $1.30 \pm 0.29$, phase II patients was $1.38 \pm 0.32$, phase III was $2.28 \pm 0.52$ and phase IV was $2.47 \pm 0.63$. The patients expression levels had significant different extents of the improvement $(\mathrm{p}<0.05)$. The Nanog gene expression in cancer tissues significantly decreased, and the data showed that Nanog levels in pulmonary adenocarcinoma and squamous lung carcinoma patients were basically the same (Table I).

Nanog expression of cells in various differentiation condition. A comparison of the Nanog detection rate in differentiation cells in pulmonary adenocarcinoma and squamous lung carcinoma yielded 33.5 and $37.8 \%$, respectively. In middleand high-differentiation cells, the Nanog detection rate was 
Table II. Nanog detection in adenocarcinoma and squamous lung carcinoma patients under various differentiation conditions.

\begin{tabular}{|c|c|c|c|c|}
\hline \multirow[b]{2}{*}{ Phase } & \multicolumn{2}{|c|}{ Pulmonary adenocarcinoma $(n=50)$} & \multicolumn{2}{|c|}{ Squamous lung carcinoma $(n=50)$} \\
\hline & Detection cases/cases & Detection rate $(\%)$ & Detection cases/cases & Detection rate $(\%)$ \\
\hline No differentiation & $8 / 9$ & 89.1 & $8 / 10$ & 82.0 \\
\hline Low differentiation & $7 / 12$ & 70.2 & $9 / 13$ & 69.4 \\
\hline Middle differentiation & $4 / 12$ & 33.5 & $4 / 11$ & $36.6^{\mathrm{a}}$ \\
\hline High differentiation & $3 / 8$ & 37.8 & $2 / 7$ & $28.8^{\mathrm{a}}$ \\
\hline
\end{tabular}

Compare the two groups of differentiation, $\chi^{2}=5.31$, ${ }^{\mathrm{a}} \mathrm{P}<0.05$; compared with low differentiation, $\chi^{2}=6.18,{ }^{\mathrm{b}} \mathrm{P}<0.05$.
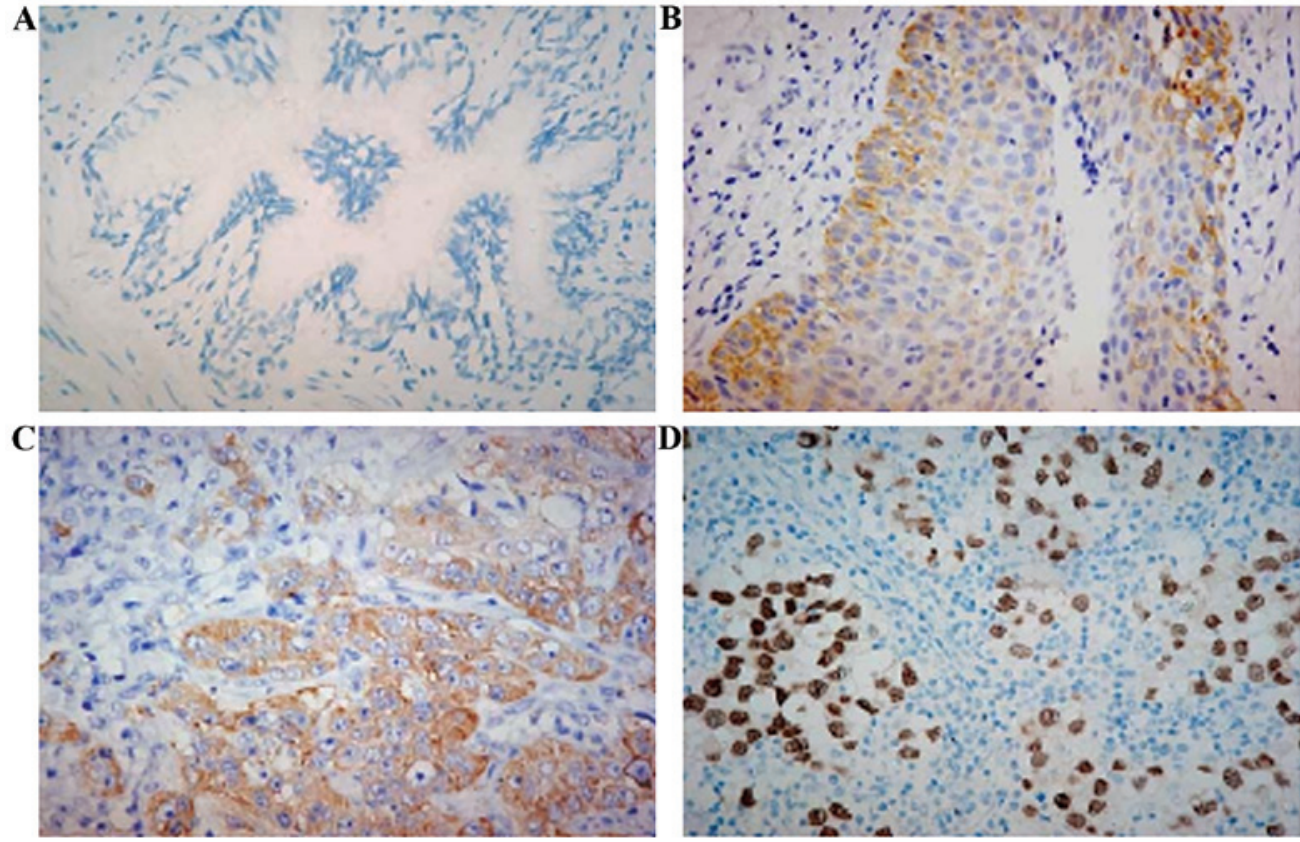

Figure 2. Nanog expression in adjacent normal tissue, benign lung cancer and lesion lung cancer tissue (immunostaining; original magnification, $\mathrm{x} 400$ ). (A) Positive staining of normal lung cells, (B) Nanog in squamous epidermis, (C) Nanog staining in squamous cell cancer, (D) Nanog staining in spermatogenous cell cancer nucleus.

relatively significantly high, while in the no and low differentiation cells, the expression was 89.1 and $70.2 \%$, respectively $(\mathrm{p}<0.05)$. In the present study, we found that Nanog is basically the same in stem cells of pulmonary adenocarcinoma and squamous lung carcinoma patients (Table II).

Investigation and observation of the patients in the present study. The patients were divided into two groups according to high or low expression of Nanog, and then followed-up for the survival rate of the two groups. As shown in Fig. 3, a high expression level of Nanog in patients had a lower meta-survival rate $(44 \%)$, and a low expression level of Nanog patients had a higher meta-survival rate $(60 \%)$, and $\chi^{2}=4.69$. $\mathrm{P}<0.05$ was considered to indicate a statistically significant difference.

\section{Discussion}

Clinical studies have found that cell heterogeneity is an important cause of tumor development (8). Certain specificity cells in the human body have a certain ability for self-renewal

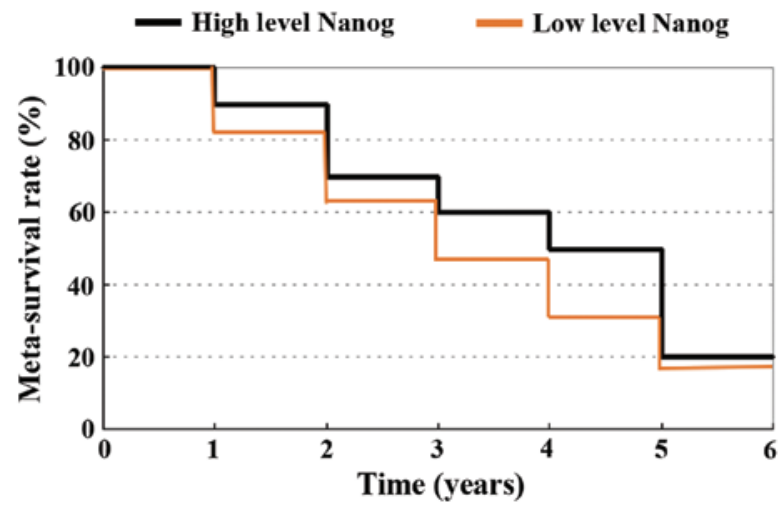

Figure 3. Observational survival rate $(\%)$ for all the patients.

and differentiation (9), and these types of cells have anti-drug and drug resistance (10), showing some characteristics of stem cells (11). Tumor stem cells are tumor cells that occur clinically, and are capable of renewal and proliferation (12). They can 
indirectly influence tumor growth, and therefore are of great significance in the control and prevention of tumor (13). Nanog expression is a transcription factor of embryonic stem cells (ESCs), and is also a type of primitive reproduction cell. It has been found that Nanog exists in embryonic stem cell, reproduction stem cell and other related tumor cells $(14,15)$. Relevant studies suggested that cancer cells in human body can grows in an uncontrollable manner with low-differentiation. The results of the present study suggest that Nanog intervention can effectively regulate human body mechanism of tumor patients, and Nanog plays an important role in the treatment process. However, there is currently no evidence showing whether the diseases are associated with Nanog (14). In the present study, we knocked out Nanog gene, and found that the tumor was inhibited after the knockout, suggesting Nanog can directly participate in human body repair treatment (15). Previous experiments found that except for repairing human stem cells, Nanog (16) can self-renew and regulate as well as differentiate. For instance, the higher the data, the stronger the ability of low- and no-differentiation of the stem cells (17).

Besides being expressed in reproductive cells and malignant tumor, Nanog is also expressed in entity tumor-like breast cancer, retinoblastoma and oral squamous cell carcinoma (18). Nanog pseudogene expression is found in cervix cancer and breast cancer (19-21). From the data of 100 cases of lung cancer in the present study, we found that Nanog gene expression was significantly higher in lung cancer tissue than in adjacent normal tissue $(\mathrm{p}<0.01)$. The data showed that there may be Nanog gene in lung cancer stem cells (LCSCS) in tissue of lung cancer patients (22). The main factor promoting lung cancer cells in human is that it can self-renew and proliferate in its LCSCS (23). When we examined the adjacent normal tissue, we found Nanog is positive in 5 cases, demonstrating this part of adjacent normal tissue may contain normal lung cancer stem cells. The present study found that Nanog gene expression is consistence with the differentiation extent of lung cancer tissue and tumor, and a positive expression rate is evident in low- and no-differentiation, but not in high-differentiation ( $p=0.0112)(24)$. We found that the Nanog gene and differentiation condition of tumor stem cells are consistent. A high expression of Nanog can maintain the low-differentiation condition of stem cells, and maintain self-renewal and proliferation of the stem cells, which is crucial in assistance to differentiation signals.

In summary, the present study found a correlation between consistency of tumor and Nanog gene expression, showing that when human cell differentiation reaches the lowest point, Nanog gene was stronger. As a newly found specific marker, the Nanog gene contributes to potential clinical prevention of lung cancer.

\section{References}

1. Mak VC, Siu MK, Wong OG, Chan KK, Ngan HY and Cheung AN: Dysregulated stemness-related genes in gynecological malignancies. Histol Histopathol 27: 1121-1130, 2012.

2. Kemmerling R, Alinger B, Dietze O, Bösmüller HC, Ocker M, Wolkersdörfer GW, Berr F, Neureiter D and Kiesslich T: Association of stem cell marker expression pattern and survival in human biliary tract cancer. Int J Oncol 41: 511-522, 2012.
3. Chiu CG, Chan SK, Fang ZA, Masoudi H, Wood-Baker R, Jones SJ, Gilks B, Laskin J and Wiseman SM: Beta-catenin expression is prognostic of improved non-small cell lung cancer survival. Am J Surg 203: 654-659, 2012

4. Xu C, Xie D, Yu SC, Yang XJ, He LR, Yang J, Ping YF, Wang B, Yang L, Xu SL, et al: $\beta$-Catenin/POU5F1/SOX2 transcription factor complex mediates IGF-I receptor signaling and predicts poor prognosis in lung adenocarcinoma. Cancer Res 73: 3181-3189, 2013

5. Nayerossadat N, Maedeh T and Ali PA: Viral and nonviral delivery systems for gene delivery. Adv Biomed Res 1: 27, 2012.

6. Levina V, Marrangoni A, Wang T, Parikh S, Su Y, Herberman R, Lokshin A and Gorelik E: Elimination of human lung cancer stem cells through targeting of the stem cell factor-c-kit autocrine signaling loop. Cancer Res 70: 338-346, 2010.

7. Meng X, Wang X and Wang Y: More than $45 \%$ of A549 and H446 cells are cancer initiating cells: evidence from cloning and tumorigenic analyses. Oncol Rep 21: 995-1000, 2009.

8. Huang D, Gao Q, Guo L, Zhang C, Jiang W, Li H, Wang J, Han X, Shi Y and Lu SH: Isolation and identification of cancer stem-like cells in esophageal carcinoma cell lines. Stem Cells Dev 18: 465-473, 2009.

9. Guzman ML, Swiderski CF, Howard DS, Grimes BA, Rossi RM, Szilvassy SJ and Jordan CT: Preferential induction of apoptosis for primary human leukemic stem cells. Proc Natl Acad Sci USA 99: 16220-16225, 2002.

10. Houghton J, Stoicov C, Nomura S, Rogers AB, Carlson J, Li H, Cai X, Fox JG, Goldenring JR and Wang TC: Gastric cancer originating from bone marrow-derived cells. Science 306 : 1568-1571, 2004.

11. Abbott BL: ABCG2 (BCRP): a cytoprotectant in normal and malignant stem cells. Clin Adv Hematol Oncol 4: 63-72, 2006.

12. Vermeulen L, De Sousa E Melo F, van der Heijden M, Cameron K, de Jong JH, Borovski T, Tuynman JB, Todaro M, Merz C, Rodermond $\mathrm{H}$, et al: Wnt activity defines colon cancer stem cells and is regulated by the microenvironment. Nat Cell Biol 12: 468-476, 2010.

13. Chen D, Zhao M and Mundy GR: Bone morphogenetic proteins. Growth Factors 22: 233-241, 2004.

14. Kim YS, Farrar W, Colburn NH and Milner JA: Cancer stem cells: potential target for bioactive food components. J Nutr Biochem 23: 691-698, 2012

15. Liu S, Dontu G, Mantle ID, Patel S, Ahn NS, Jackson KW, Suri $\mathrm{P}$ and Wicha MS: Hedgehog signaling and Bmi-1 regulate self-renewal of normal and malignant human mammary stem cells. Cancer Res 66: 6063-6071, 2006.

16. Lessard J and Sauvageau G: Bmi-1 determines the proliferative capacity of normal and leukaemic stem cells. Nature 423: 255-260, 2003

17. Stovall DB, Wan M, Zhang Q, Dubey P and Sui G: DNA vector-based RNA interference to study gene function in cancer. J Vis Exp 64: e4129, 2012.

18. Tsai LL, Yu CC, Chang YC, Yu CH and Chou MY: Markedly increased Oct4 and Nanog expression correlates with cisplatin resistance in oral squamous cell carcinoma. J Oral Pathol Med 40: 621-628, 2011.

19. Gu TT, Liu SY and Zheng PS: Cytoplasmic NANOG-positive stromal cells promote human cervical cancer progression. Am J Pathol 181: 652-661, 2012.

20. Nagata T, Shimada Y, Sekine S, Hori R, Matsui K, Okumura T, Sawada S, Fukuoka J and Tsukada K: Prognostic significance of NANOG and KLF4 for breast cancer. Breast Cancer 21: 96-101, 2014.

21. Lu X, Mazur SJ, Lin T, Appella E and Xu Y: The pluripotency factor nanog promotes breast cancer tumorigenesis and metastasis. Oncogene 33:2655-2664, 2014.

22. Primo MN, Bak RO and Mikkelsen JG: Lentiviral vectors for cutaneous RNA managing. Exp Dermatol 21: 162-170, 2012.

23. Cavazza A, Moiani A and Mavilio F: Mechanisms of retroviral integration and mutagenesis. Hum Gene Ther 24: 119-131, 2013.

24. Rodriguez GP, Song JB and Crouse GF: Transformation with oligonucleotides creating clustered changes in the yeast genome. PLoS One 7: e42905, 2012. 